\title{
Endocrine surgery during COVID-19 pandemic: do we need an update of indications in Italy?
}

\author{
Celestino Pio Lombardi ${ }^{1}$ Annamaria $\mathrm{D}^{\prime}$ Amore $^{1} \cdot$ Giorgio Grani $^{2} \cdot$ Valeria Ramundo $^{2} \cdot$ Mauro Boscherini $^{1}$. \\ Luca Gordini ${ }^{1} \cdot$ Federica Marzi $^{1} \cdot$ Silvia Tedesco ${ }^{1} \cdot$ Raffaella Bocale $^{1}$
}

Received: 27 April 2020 / Accepted: 15 May 2020 / Published online: 4 June 2020

(c) Springer Science+Business Media, LLC, part of Springer Nature 2020

\begin{abstract}
The ongoing spread of the coronavirus disease 2019 (COVID-19) caused by severe acute respiratory syndrome coronavirus2 (SARS-CoV-2) poses a significant threat to global health. As the coronavirus outbreak began spreading, hospitals were forced to relocate resources to treat the growing number of COVID-19 patients. As a consequence, doctors across the country canceled tens of thousands of nonurgent surgeries. However, recognizing that the COVID-19 situation may be highly variable and fluid in different communities across the country, elective surgery could be still allowed in some centers for patients included in the high-priority class. The majority of endocrine disorders requiring surgical treatment in patients identifiable as first-priority class, or needing hospitalization within 30 days, are generally represented by malignant thyroid tumors, hyperthyroidism, hyperparathyroidism, and some adrenal disorders. The need for urgent intervention is evaluated on a case-by-case basis according to the severity of the symptoms, the likelihood of progression, and global clinical judgment. On the basis of the above indications, during the last 4 weeks, we performed 18 planned surgical treatments in patients with thyroid cancer (total thyroidectomies, plus lymph node dissection if needed) or multinodular toxic goiter. In no case, postoperative ventilatory support was needed, and the average hospital stay was 3 days. The negative COVID-19 status for all the treated patients was appropriately evaluated beforehand. Nobody knows how long the current COVID-19 pandemic will be lasting. Certainly, we will be requested in the next future to incrementally offer surgical services for endocrine disorders that have been deferred for the COVID-19 pandemic.
\end{abstract}

Keywords COVID-19 $\cdot$ Endocrine surgery $\cdot$ Thyroid cancer $\cdot$ Endocrine emergencies

Coronavirus disease 2019 (COVID-19) caused by severe acute respiratory syndrome coronavirus-2 (SARS-CoV-2) poses a significant threat to global health [1]. On January 30, 2020, the World Health Organization designated an outbreak of a novel coronavirus not seen before in humans to be a "public health emergency of international concern." Within the first 2 months of the outbreak, the epidemic spread rapidly around the country and the world. As of March 8, 2020, a total of 80,868 confirmed cases and 3101

Raffaella Bocale

raffaella.bocale@policlinicogemelli.it

1 Division of Endocrine Surgery, "Agostino Gemelli" School of Medicine, University Foundation Polyclinic, Catholic University of the Sacred Heart, Rome, Italy

2 Department of Translational and Precision Medicine, "Sapienza" University of Rome, Rome, Italy deaths had been reported in the Chinese mainland by the National Health Commission of China, and 90 other countries are affected [2]. It was followed by the declaration of a pandemic on March 11, 2020 [3, 4].

Three major trajectories for COVID-19 have been described: a mild disease with upper respiratory symptoms, nonsevere pneumonia, and severe pneumonia complicated by acute respiratory distress syndrome, necessitating aggressive resuscitative measures $[5,6]$, in $17-29 \%$ of patients $[7,8]$. Other complications include secondary bacterial infection, acute kidney injury, septic shock, ventilatorassociated pneumonia, and cardiac injury [7, 8]. In most cases, patients can recover gradually without sequelae. However, similar to severe acute respiratory syndrome coronavirus (SARS-CoV) and Middle East respiratory syndrome coronavirus (MERS-CoV), COVID-19 is also associated with high morbidity and mortality in patients with severe cases [6]. With an unprecedented number of individuals under travel restrictions or quarantine, and no known 
effective treatment or vaccine yet available, COVID-19 has proven a formidable adversary [9].

As the coronavirus outbreak began spreading, hospitals were forced to relocate resources to treat the growing number of COVID-19 patients. As a consequence, doctors across the country canceled tens of thousands of nonurgent surgeries. International societies of surgeons recently published elective case-triage guidelines for surgical care during the COVID-19 pandemic to help institutions and providers who are facing a rising burden of hospitalized COVID-19 patients, and a higher prevalence of community infection [10, 11]. However, recognizing that the COVID19 situation may be highly variable and fluid in different communities across the country, guidelines underline that the decision-making process should consider the acuity of the local COVID-19 condition [10, 11]. Here, we illustrate the decision-making process to schedule elective surgery for endocrine disorders during the COVID-19 pandemic at our Endocrine Surgery Unit of Policlinico "Agostino Gemelli" Foundation, a central Italy Hub for surgical treatment of endocrine diseases.

\section{The experience of the Endocrine Surgery Unit in an Italian Covid Hub hospital}

According to the American College of Surgeons guidelines [10], the Policlinico "Agostino Gemelli" Foundation is currently in a pre-emergency state: it is still possible to guarantee ventilatory assistance in intensive care, and the local trend of Sars-COV2 infections is stable, not exponential. Thus, elective surgery is still allowed for patients included in the priority class as defined on the basis of the Italian National Plan for the Management of Waiting Lists 2019/2021 [12]. The majority of endocrine disorders requiring surgical treatment in patients identifiable as first-priority class, or needing hospitalization within 30 days, are generally represented by malignant thyroid tumors, hyperthyroidism, hyperparathyroidism, and some adrenal disorders. There are no data on the prognostic impact of delaying surgical treatment for these diseases: the need for urgent intervention is evaluated on a case-by-case basis according to the severity of the symptoms, the likelihood of progression and global clinical judgment.

Among thyroid neoplasms, anaplastic, poorly differentiated, and medullary thyroid tumors represent compelling indications for immediate surgical treatment [13]. Although most thyroid tumors are differentiated and have a good prognosis, attention must be focused on the preoperative risk stratification. Since about half of the currently diagnosed thyroid tumors in Italy are small, equal to or less than $1 \mathrm{~cm}$ [14], this is an appropriate time to propose to patients more conservative approaches, including active surveillance [15]. However, it requires an accurate workup; surgery is recommended for patients with clinical evidence of lateral neck lymph node metastases, or when extrathyroidal extension is suspected.

Among nonneoplastic thyroid diseases, the main indication for urgent thyroidectomy is represented by refractory thyrotoxicosis, especially in patients with severe, lifethreatening hypermetabolic state and/or at risk of complications [16, 17]. Elderly patients often manifest with mild symptoms, despite a high risk to develop cardiovascular complications [16, 17].

A large, compressive goiter may occasionally lead to acute respiratory insufficiency [18-20]. Acute compression of the airway and dyspnea is mostly secondary to the rapid enlargement of the thyroid mass. Obstructive symptoms, including shortness of breath, are a clear indication for surgery $[18,19,21]$. Nevertheless, due to its slow development and patient adaptation, tracheal compression often remains unrecognized [20]. However, several studies have shown that thyroidectomy improves tracheal airflow [22, 23].

Among parathyroid disorders, hypercalcemic crisis or severe hypercalcemia $(>13 \mathrm{mg} / \mathrm{dl})$ represents a lifethreatening emergency $[24,25]$. This endocrine emergency portends excellent outcomes if rapid diagnosis, medical treatment, and definitive surgical treatment are expedited [25, 26].

Among adrenal diseases, malignant tumors are compelling indications for urgent surgical treatment. Pheochromocytoma and paraganglioma are potentially lifethreatening conditions often needing a prompt surgical treatment [27].

On the basis of the above indications, during the last 4 weeks, we performed 18 planned surgical treatments in 14 patients with thyroid cancer (total thyroidectomies, plus lymph node dissection if needed) and 4 patients with multinodular goiter (2 toxic goiters). In no case, postoperative ventilatory support was needed, and the average hospital stay was 3 days. The negative COVID-19 status for all the treated patients was appropriately assessed beforehand by clinical evaluation and negative nasopharyngeal swab RTPCR assay.

This amount of activity corresponds to about one-third of the usual surgical volume in a comparable time frame in our Endocrine Surgery Unit. No patients with either parathyroid or adrenal gland diseases requiring urgent surgical treatment were enlisted in the priority class during the above indicated period. All the nonurgent procedures $(n=$ 79) were postponed, while 2 patients enlisted in the priority class for thyroid cancer refused the intervention because of their worry to contract SARS-CoV-2 infection during the hospital stay. 


\section{Looking (hopeful) to the next future}

Nobody knows how long the current COVID-19 pandemic will be lasting. A number of research groups are already prospectively tracking the impact of COVID-19 on both elective surgical footprints, and emergency-operative (and nonoperative) surgical volumes and outcomes [28]. We acknowledge that these challenging times require extraordinary efforts. As surgeons, many of us are used to work in suboptimal conditions and challenging scenarios. Maintaining the health and strength of our clinical workforce is critical to avoiding the collapse of our health care system. The experience of our colleagues in Singapore and Hong Kong in protecting their health care workers is quite reassuring [29]. We will be able to provide excellent care, planning routine and procedures beforehand, still protecting the safety and health of our colleagues. However, in just a few weeks, COVID-19 has driven a rapid and radical transformation of medical approach. In the midst of the COVID-19 pandemic, physician practices have been forced to turn from in-person care to telehealth in primary care practices [29]. The speed of the transition has been dizzying. Changes that would typically encompass months of planning, pilot testing, and education have been compressed into days [30]. In the surgical setting, all the procedures performed in an epicenter of the COVID-19 pandemic, irrespective of the known or suspected COVID-19 status of the patients, should be regarded as high risk, and protection of the surgical team at the bedside should be at the highest level [31]. Robot-assisted surgery may help to reduce hospital stay for patients that urgently need surgery, thus reducing the risk of nosocomial infections, and making room for COVID-19 patients. In comparison with open or conventional laparoscopic surgery, robot-assisted surgery potentially reduces not only contamination with body fluids and surgical gasses of the surgical area, but also the number of directly exposed medical staff [31]. This approach is well established also for endocrine surgery [32, 33]. Anyway, being a doctor will never be probably the same here forward.

\section{Compliance with ethical standards}

Conflict of interest The authors declare that they have no conflict of interest.

Publisher's note Springer Nature remains neutral with regard to jurisdictional claims in published maps and institutional affiliations.

\section{References}

1. N. Zhu, D. Zhang, W. Wang, X. Li, B. Yang, J. Song, X. Zhao, B. Huang, W. Shi, R. Lu, P. Niu, F. Zhan, X. Ma, D. Wang, W. Xu,
G. Wu, G.F. Gao, W. Tan, China Novel Coronavirus Investigating and Research Team. A novel coronavirus from patients with pneumonia in China, 2019. N. Engl. J. Med. 382(8), 727-733 (2020)

2. M. Zhou, X. Zhang, J. Qu. Coronavirus disease 2019 (COVID-19): a clinical update. Front. Med. (2020). https://doi.org/10.1007/ s11684-020-0767-8

3. World Health Organization. Statement on the second meeting of the International Health Regulations. Emergency Committee regarding the outbreak of novel coronavirus (2019-nCoV). (2005). https://www.who.int/news-room/detail/30-01-2020-statement-onthe-second-meeting-of-the-international-health-regulations(2005)-emergency-committee-regarding-the-outbreak-of-novelcoronavirus-(2019-ncov). Published January 30, 2020. Accessed 18 Feb 2020

4. World Health Organization. WHO Director-General's opening remarks at the media briefing on COVID-19 (March 11 2020). https://www.who.int/dg/speeches/detail/who-director-general-sopening-remarks-atthe-media-briefing-on-covid-19---11-march2020. Published March 11, 2020. Accessed 20 Mar 2020

5. D.L. Heymann, N. Shindo, COVID-19: what is next for public health? The Lancet. 395(10224), 542-545 (2020)

6. S. Chavez, B. Long, A. Koyfman, S.Y. Lyang, Coronavirus Disease (COVID-19): a primer for emergency physicians. Am. J. Emerg. Med. (2020). https://doi.org/10.1016/j.ajem.2020.03.036

7. C. Huang, Y. Wang, X. Li, L. Ren, J. Zhao, Y. Hu, L. Zhang, G. Fan, J. Xu, X. Gu, Z. Cheng, T. Yu, J. Xia, Y. Wei, W. Wu, X. Xie, W. Yin, H. Li, M. Liu, Y. Xiao, H. Gao, L. Guo, J. Xie, G. Wang, R. Jiang, Z. Gao, Q. Jin, J. Wang, B. Cao, Clinical features of patients infected with 2019 novel coronavirus in Wuhan, China. The Lancet. 395(10223), 497-506 (2020)

8. N. Chen, M. Zhou, X. Dong, J. Qu, F. Gong, Y. Han, Y. Qiu, J. Wang, Y. Liu, Y. Wei, J. Xia, T. Yu, X. Zhang, L. Zhang, Epidemiological and clinical characteristics of 99 cases of 2019 novel coronavirus pneumonia in Wuhan, China: a descriptive study. The Lancet. 395(10223), 507-513 (2020)

9. CDC. 2019 Novel Coronavirus (2019-nCoV) Prevention \& Treatment. Centers for Disease Control and Prevention. https://www.cdc.gov/coronavirus/2019-ncov/about/prevention-trea tment.html. Published February 11, 2020. Accessed 19 Mar 2020

10. COVID 19: Elective Case Triage Guidelines for Surgical Care Cancer Surgery. https://www.facs.org/covid-19/clinical-guidance/ elective-case/cancer-surgery

11. Updated Intercollegiate General Surgery Guidance on COVID-19. https://www.rcseng.ac.uk/coronavirus/joint-guidance-for-surgeonsv2/

12. 13/08/2019 - BOLLETTINO UFFICIALE DELLA REGIONE LAZIO - N. 65- PIANO NAZIONALE DI GOVERNO DELLE LISTE DI ATTESA PER IL TRIENNIO. (2019-2021). http://www.regione.lazio.it/binary/rl_sanita/tbl_normativa/SAN_ DCA_U00302_25_07_2019.pdf

13. S. Filetti, C. Durante, D. Hartl, S. Leboulleux, L.D. Locati, K. Newbold, M.G. Papotti, A. Berruti, Thyroid cancer: ESMO Clinical Practice Guidelines for diagnosis, treatment and followup †. Ann. Oncol. 30(12), 1856-1883 (2019)

14. L. Lamartina, C. Durante, G. Lucisano, G. Grani, R. Bellantone, C.P. Lombardi, A. Pontecorvi, E. Arvat, F. Felicetti, M.C. Zatelli, R. Rossi, E. Puxeddu, S. Morelli, M. Torlontano, U. Crocetti, T. Montesano, R. Giubbini, F. Orlandi, G. Aimaretti, F. Monzani, M. Attard, C. Francese, A. Antonelli, P. Limone, R. Rossetto, L. Fugazzola, D. Meringolo, R. Bruno, S. Tumino, G. Ceresini, M. Centanni, S. Monti, D. Salvatore, G. Spiazzi, C. Mian, L. Persani, D. Barbaro, A. Nicolucci, S. Filetti, Are evidence-based guidelines reflected in clinical practice? An analysis of prospectively collected data of the italian thyroid cancer observatory. Thyroid. 27(12), 1490-1497 (2017) 
15. V. Ramundo, M. Sponziello, R. Falcone, A. Verrienti, S. Filetti, C. Durante, G. Grani, Low-risk papillary thyroid microcarcinoma: Optimal management toward a more conservative approach. J. Surg. Oncol. 121(6), 958-963 (2020)

16. B. Goichot, P. Caron, F. Landron, S. Bouée, Clinical presentation of hyperthyroidism in a large representative sample of outpatients in France: relationships with age, aetiology and hormonal parameters. Clin. Endocrinol. (2015). https://doi.org/10.1111/cen.12816

17. K. Boelaert, B. Torlinska, R.L. Holder, J.A. Franklyn, Older subjects with hyperthyroidism present with a paucity of symptoms and signs: a large cross-sectional study. J. Clin. Endocrinol. Metab. 95, 2715-2726 (2010)

18. W.T. Shen, E. Kebebew, Q.Y. Duh, O.H. Clark, Predictors of airway complications after thyroidectomy for substernal goiter. Arch. Surg. 139, 656-659 (2004)

19. P.G. Gauger, A.I. Guinea, T.S. Reeve, L.W. Delbridge, The spectrum of emergency admissions for thyroidectomy. Am. J. Emerg. Med. 17(6), 591-593 (1999)

20. S.K. Menon, V.S. Jagtap, V. Sarathi, A.R. Lila, T.R. Bandgar, P. S. Menon, N.S. Shah, Prevalence of upper airway obstruction in patients with apparently asymptomatic euthyroid multi nodular goitre. Ind. J. Endocrinol. Metab. 15, S127-S131 (2011)

21. L.R. Sajja, G.C. Mannam, S. Sompalli, C.S. Simhadri, A. Hasan, Multinodular goiter compressing the trachea following open heart surgery. Asian Cardiovasc. Thorac. Ann. 14, 416-417 (2006)

22. T.K. Thusoo, U. Gupta, K. Kochhar, H.S. Hira, Upper airway obstruction in patients with goiter studies by flow volume loops and effect of thyroidectomy. World J. Surg. 24, 1570-1572 (2000)

23. J.R. Sorensen, J.F. Lauridsen, H. Døssing, N. Nguyen, L. Hegedüs, S.J. Bonnema, C. Godballe, Thyroidectomy improves tracheal anatomy and airflow in patients with nodular goiter: a prospective cohort study. Eur. Thyroid J. 6(6), 307-314 (2017)

24. G.W. Edelson, M. Kleerekoper, Hypercalcemic crisis. Med. Clin. North. Am. 79(1), 79-92 (1995)
25. S. Ahmad, G. Kuraganti, D. Steenkamp, Hypercalcemic crisis: a clinical review. Am. J. Med. 128(3), 239-245 (2015)

26. R. Phitayakorn, C.R. McHenry, Hyperparathyroid crisis: use of bisphosphonates as a bridge to parathyroidectomy. J. Am. Coll. Surg. 206(6), 1106-1115 (2008)

27. J.W. Lenders, Q.Y. Duh, G. Eisenhofer, A.P. Gimenez-Roqueplo, S.K. Grebe, M.H. Murad, M. Naruse, K. Pacak, W.F. Young Jr., Endocrine Society. Pheochromocytoma and paraganglioma: an endocrine society clinical practice guideline. J. Clin. Endocrinol. Metab. 99(6), 1915-1942 (2014)

28. C.G. Ball, COVID-19: A Time of Crisis, but Also of Surgical Opportunity and Optimism. Can. J. Surg. (2020). https://doi.org/ 10.1503/cjs.003920

29. A. Gawande, Keeping the coronavirus from infecting healthcare workers: what Singapore's and Hong Kong's success is teaching us about the pandemic. The New Yorker (March 21, 2020). https://www.newyorker.com/news/news-desk/keepingthe-coronavirusfrom-infecting-health-care-workers. Accessed 23 Mar 2020

30. A. Mehrotra, K. Ray, D.M. Brockmeyer, M.L. Barnett, J.A. Bender, Rapidly Converting to "Virtual Practices": Outpatient Care in the Era of Covid-19. https://doi.org/10.1056/CAT.20. 0091. Downloaded from catalyst.nejm.org on April 4, 2020

31. R. Kimmig, R.H.M. Verheijen, M. Rudnicki, SERGS Council. Robot assisted surgery during the COVID-19 pandemic, especially for gynecological cancer: a statement of the Society of European Robotic Gynaecological Surgery (SERGS). J. Gynecol. Oncol. (2020). https://doi.org/10.3802/jgo.2020.31.e59

32. M.E. Garstka, E.S. Alameer, S.A. Awwad, E. Kandil, Conventional robotic endoscopic thyroidectomy for thyroid cancer. Endocrinol. Metab. Clin. North. Am. 48(1), 153-163 (2019)

33. C. Nomine-Criqui, L. Demarquet, M.L. Schweitzer, M. Klein, L. Brunaud, F. Bihain, Robotic adrenalectomy: when and how?. Gland Surg. 9(Suppl 2), S166-S172 (2020) 